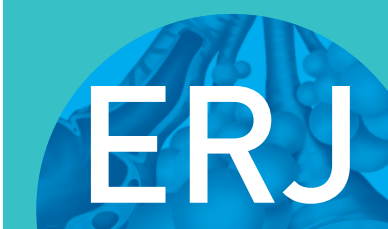

open research

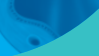

\title{
European Respiratory Society International Congress 2018: Allied Respiratory Professionals' report of highlighted sessions
}

\author{
Matthew Rutter ${ }^{1,11}$, Carlos Augusto Camillo $2,3,11$, Peter Coss ${ }^{4,11}$, \\ Andreja Sajnic $\mathbb{1}^{5,11}$, Aisling McGowan ${ }^{6}$, Daniel Langer ${ }^{7}$, Jana De Brandt ${ }^{8}$ and \\ Christian Osadnik (10) 90,11
}

Affiliations: ${ }^{1}$ Lung Function Dept, Cambridge University Hospitals, Addenbrookes Hospital, Cambridge, UK. ${ }^{2}$ University of Londrina, Dept of Physiotherapy, Londrina, Brazil. ${ }^{3}$ University Pitágoras UNOPAR, Dept of Rehabilitation Sciences, Londrina, Brazil. "Dept of Respiratory Medicine, St James Hospital, Dublin, Ireland. ${ }^{5}$ Dept for Respiratory Diseases "Jordanovac", University Hospital Center, Zagreb, Croatia. ${ }^{6}$ Dept of Respiratory and Sleep Diagnostics, Connolly Hospital, Blanchardstown, Dublin, Ireland. ${ }^{7}$ KU Leuven University of Leuven, Dept of Rehabilitation Sciences, Leuven, Belgium. ${ }^{8}$ REVAL - Rehabilitation Research Center, BIOMED - Biomedical Research Institute, Faculty of Rehabilitation Sciences, Hasselt University, Diepenbeek, Belgium. ${ }^{9}$ Dept of Physiotherapy, Monash University, Melbourne, Australia. ${ }^{10}$ Monash Lung and Sleep, Monash Health, Melbourne, Australia. ${ }^{11}$ These authors contributed equally.

Correspondence: Jana De Brandt, Campus Diepenbeek, Hasselt University, Agoralaan Building A, 3590 Diepenbeek, Belgium. E-mail: jana.debrandtQuhasselt.be

ABSTRACT This article provides an overview of outstanding sessions that were supported by Assembly 9 during the recent European Respiratory Society International Congress in Paris, France. Session content was mainly targeted at allied health professionals such as respiratory physiologists, respiratory physiotherapists and respiratory nurses. Recent developments and novel findings related to pulmonary function testing, respiratory muscle function assessments and treatment, and multidimensional and multidisciplinary approaches to the assessment and management of dyspnoea were the focus of these sessions and are summarised here.

@ERSpublications

An overview of outstanding sessions that were supported by Assembly 9 during the 2018 European Respiratory Society International Congress in Paris, France. http://ow.ly/OO8P30mXs3q

Cite this article as: Rutter M, Camillo CA, Coss P, et al. European Respiratory Society International Congress 2018: Allied Respiratory Professionals' report of highlighted sessions. ERJ Open Res 2019; 5: 00182-2018 [https://doi.org/10.1183/23120541.00182-2018].

Copyright $\odot$ ERS 2019. This article is open access and distributed under the terms of the Creative Commons Attribution Non-Commercial Licence 4.0. 


\section{Introduction}

The 2018 European Respiratory Society (ERS) International Congress offered allied health professionals a wide range of interesting sessions. Early career members of assembly 9 , including respiratory physiologists, respiratory physiotherapists and respiratory nurses were asked to report on an educational workshop on body plethysmography, an exciting "pro/con" debate on lung function testing and the two well-attended symposia on respiratory muscle function, and multidimensional and multidisciplinary approaches to managing dyspnoea. This report attempts to succinctly summarise some of the latest scientific and clinical insights gained from each session, targeting delegates who were present in Paris as well as those unable to attend in person.

\section{Skills workshop on body plethysmography}

In 2018, specialists in respiratory physiology from group 9.1 developed and delivered a skills workshop focused on improving knowledge, theory and practical skills to perform body plethysmography testing in accordance with American Thoracic Society/ERS technical standards [1]. Airways resistance techniques were also discussed. Workshops were chaired by Jellien Makonga-Braaksma and Frans De Jongh.

The aim of the workshop was to better inform current practice through small group work targeting the following four key areas: 1) quality control; 2) technical aspects and system settings; 3) test performance; and 4) clinical interpretation. Delegates were provided with a useful infographic summarising key points from each workstation (table 1).

\section{Quality control}

M. Swanney, Christchurch, New-Zealand and F. Burgos, Barcelona, Spain

Quality control is essential to ensure a robust method for measurement as the results are only as good as the quality assurance process that is in practice. Poor quality control can lead to errors in measurement. The body plethysmograph requires three verification checks of volume measurement, pressure transducer and isothermal leak in order to produce accurate results. The system settings, measurement evaluation and calculations are vital to understanding how values are determined and influenced during testing.

\section{Technical aspects and system settings}

K. De Soomer, Burcht, Belgium and E. Oostveen, Edegem, Belgium

The technical aspects of measurement relate to the principles behind the measurement technique with regards to the measurement of lung volumes and airways resistance. The technique was first developed by DuBors et al. [2, 3] in 1956 and is based on Boyle's Law: pressurexvolume=constant under isothermal

\section{TABLE 1 Summary of the skills workshop in body plethysmography}

\begin{tabular}{|c|c|c|c|}
\hline Calibration, QC and settings & Technical aspects & $\begin{array}{l}\text { Standardisation of test } \\
\text { performance }\end{array}$ & Reporting \\
\hline $\begin{array}{l}\text { Check ambient conditions } \\
\text { Perform three flow volume } \\
\text { calibrations of sensor e.g. } \\
\text { pneumotach } \\
\text { Perform leak time verification } \\
\text { and time constant } \\
\text { Perform pressure sensor } \\
\text { verification } \\
\text { Perform BIO QC to check } \\
\text { normal values } \\
\text { Review system settings for } \\
\text { shutter time and calculation of } \\
\text { RV and TLC } \\
\text { Quarterly perform isothermal } \\
\text { calibration as part of the QA } \\
\text { programme (known volume/ } \\
\text { resistance method) }\end{array}$ & $\begin{array}{l}\text { Ensure adequate thermal } \\
\text { equilibration } \\
\text { Check internal speaker is } \\
\text { working and communication } \\
\text { with patient is clear } \\
\text { Ensure mouthpiece is an } \\
\text { appropriate size and fit for the } \\
\text { patient and adjust the arm to } \\
\text { the most comfortable position } \\
\text { for patients upright sitting } \\
\text { position } \\
\text { Ensure there is a filter and nose } \\
\text { peg available } \\
\text { System has been calibrated } \\
\text { successfully } \\
\text { Operator understands the } \\
\text { technical aspects of the tests }\end{array}$ & $\begin{array}{l}\text { Test performance as per } \\
\text { international and national } \\
\text { recommendations } \\
\text { Enter patient demographic data } \\
\text { into system software } \\
\text { Consider patient limitations } \\
\text { Explain the purpose of the test } \\
\text { and most suitable method } \\
\text { Check sitting position, position of } \\
\text { sensor mounting arm and that } \\
\text { patient can hold their cheeks } \\
\text { Close the door and explain the } \\
\text { test again during thermal } \\
\text { equilibrium } \\
\text { Perform linked or separated } \\
\text { manoeuvre: } \\
\text { Airways resistance } \\
\text { TGV } \\
\text { VC manoeuvre }\end{array}$ & $\begin{array}{l}\text { Airways resistance should } \\
\text { be a uniform } \\
\text { overlapping shape of } \\
\text { consistent breaths } \\
\text { Report median breath } \\
\text { from median trial } \\
\text { Report sReff } \\
\text { TGV should occur at the } \\
\text { end of a tidal breath } \\
\text { ERV should be } \\
\text { reproducible } \\
\text { VC should be consistent } \\
\text { with largest recorded } \\
\text { Minimum three technically } \\
\text { acceptable manoeuvres } \\
\text { within } 5 \% \text { variation }\end{array}$ \\
\hline
\end{tabular}

QC: quality control; sReff: effective specific airways resistance; TGV: thoracic gas volume; ERV: expiratory reserve volume; VC: vital capacity; BIO QC: biological quality control; RV: residual volume; TLC: total lung capacity; QA: quality assurance. 
conditions. The body plethysmograph measures changes in both pressure and volume to determine thoracic gas volume (TGV) at any point of lung inflation. TGV is measured at the end of a tidal breath; that is, at functional residual capacity (FRC). Expiratory reserve volume (ERV) is measured after TGV and can be used to calculate residual volume (RV): TGV-ERV=RV. The addition of a vital capacity (VC) manoeuvre allows for total lung capacity (TLC) to be derived: VC+RV=TLC. Airways resistance can also be measured but must be performed prior to lung volumes. In order to inhale, alveolar pressure must decrease below atmospheric pressure, resulting in a proportional increase in box pressure (Pbox). There is also a resulting volume change measured at the mouth $(V \mathrm{~m})$, and the difference between $\Delta P$ box and $\Delta V \mathrm{~m}$ is the specific airways resistance ( $s R \mathrm{aw})$. $s R$ aw is expressed commonly as effective ( $s R$ eff) or total ( $s R$ tot) depending on which part of the airways resistance loop is measured.

\section{Standardisation of test performance}

M. Rutter, Cambridge, UK and A. McGowan, Dublin, Ireland

A standardised method of test performance is essential for reproducible results. Test information should be communicated clearly and concisely in simple terms to the subject. The skill of testing is the recognition of performance errors and the ability to clearly rectify these using a standard approach in subjects that struggle with the standard technique.

\section{Clinical interpretation}

G. Garcia, Le Kremlin-Bicêtre, France and K. Sylvester, Cambridge, UK

Interpretation of body plethysmography results requires understanding the orientation of values on the lung function report and there is a case for prioritising interpretation via "standardised residuals" over "percentage predicted" values. Results present differently based on differing pathophysiology, in terms of obstructive versus restrictive lung disease. There are several key parameters for lung volume measurement and airways resistance: TLC, RV, VC, FRC, ERV, RV/TLC, FRC/TLC, sReff and $s$ Rtot. In addition to the values, pattern recognition of the changes in airways resistance loops, thoracic gas volume manoeuvres and volume-time curve, based on differing pathophysiology, is important. Results range from normal, restrictive, mixed and varying degrees of obstruction with related gas trapping and hyperinflation.

\section{Concluding remarks}

Overall, attendees were presented with a comprehensive overview of all aspects required to perform and interpret body plethysmography in accordance with current best practice. Unique access to experts sharing their knowledge and experience was of particular benefit to those in attendance. Many delegates commented upon the usefulness of the workshop and a desire for more test procedures to be presented in a similar way. We hope to see a gas diffusion workshop at next year's Congress!

\section{"Pro/con" debate on current and evolving tests in lung function}

Current and evolving tests in lung function were discussed at through a spirited and enlightening "pro/con" style debate.

\section{FEV1 is helpful in respiratory medicine}

R. Rodriguez Roisin, Barcelona, Spain and O. Usmani, London, UK

R. Rodriguez Roisin on the "pro" side argued that clinical evidence to date shows forced expiratory volume in $1 \mathrm{~s}(\mathrm{FEV} 1)$ to be a vital outcome of chronic airways disease and a helpful parameter for long-term follow-up of patients with chronic obstructive pulmonary disease (COPD). According to the Global Initiative for Chronic Obstructive Lung Disease, the diagnosis of COPD in any patient is made in the presence of symptoms along with exposure to risk factors, after spirometric assessment [4]. Therefore, quality spirometry and the accurate determination of FEV 1 is one vital component in the diagnosis of COPD. The basis of treatment in COPD is then guided by the assessment of symptoms, shortness of breath and quality of life, and not by spirometry in isolation [4]. The course of airflow obstruction is not fixed and changes in FEV1 are variable over time. Data from Vestbo et al. [5] in the ECLIPSE study showed that the rate of change in FEV1 was greatest among current smokers, patients with bronchodilator reversibility, and patients with emphysema. Long-term follow-up of FEV1 in patients with chronic lung disease is important because its changes over time can influence a variety of management decisions that impact upon prognosis.

O. Usmani on the "con" side presented the caveats of treating patients by numbers (specifically the FEV1). He pointed to Nishimura et al. [6] and their study that indicated that dyspnoea is a better predictor of 5 -year survival than measures of airways obstruction in patients with COPD. In eosinophilic asthmatics, mepolizumab has been shown to improve exacerbation rates but does not show any consistent effect on objective measures such as FEV1 $[7,8]$. O. Usmani referenced the clinical utility of forced vital capacity 
(FVC) (measured during the same manoeuvre as FEV1). BURNey and Hooper [9] in their general population sample from the USA indicated that FVC could predict survival in asymptomatic adults without a chronic respiratory diagnosis or persistent respiratory symptoms. The fully adjusted hazard ratio associated with high FVC was 0.90 in men (95\% CI $0.80-1.00 ; p=0.049$ ) and 0.82 in women (95\% CI $0.70-0.95 ; \mathrm{p}=0.01)$. This compares with 0.98 for FEV1 in men $(95 \%$ CI $0.90-1.07 ; \mathrm{p}=0.72)$ and 1.01 in women (95\% CI 0.89-1.15; p=0.84). In this study the association between FVC and survival could not be explained by age, anthropometry, smoking, income occupation or blood pressure.

\section{Forced oscillometry}

R. Dandurand, Beaconsfield, Canada and P. Calverley, Liverpool, UK

Discussion was led on the "pro" side by R. Dandurand arguing that "the technique is now ready for screening respiratory disease". Setting out the clinical utility of the technique, he quoted KoHLHäUfl et al. [10] and their study of the effects of bronchial challenge with methacholine in healthy nonsmokers and asymptomatic smokers comparing FEV1 and oscillometry measures. This study found that resistance and reactance at low frequencies showed a three to four times higher post-challenge reaction compared with FEV1. Pre- and post-challenge FEV1 did not correlate with resistance and reactance over the whole frequency spectrum. R. Dandurand also discussed data from a study by OppenheImer et al. [11] that looked at oscillometry in symptomatic first responders (in the presence of normal spirometry) following exposure to World Trade Centre dust. These researchers found that mean resistance at $5 \mathrm{~Hz}, 5-20 \mathrm{~Hz}$ and reactance area were elevated (mean \pm SE $4.36 \pm 0.12 \mathrm{cmH}_{2} \mathrm{O} \cdot \mathrm{L} \cdot \mathrm{s}^{-1}, 0.86 \pm 0.05 \mathrm{cmH}_{2} \mathrm{O} \cdot \mathrm{L} \cdot \mathrm{s}^{-1}$ and $6.12 \pm 0.50 \mathrm{~cm} \mathrm{H} \mathrm{H}_{2} \mathrm{O} \cdot \mathrm{L} \cdot \mathrm{s}^{-1}$, respectively). In this study resistance and reactance where shown to be normalised after bronchodilation. R. Dandurand reported that since 2016 all manufacturers have been working together on an oscillometry harmonisation project to standardise outputs between devices. The deadline for harmonisation and retesting is 2020 .

P. Calverley on the "con" side cautioned that oscillometry is not interchangeable with spirometry and as yet there are no data to support oscillometry for screening in a population of individuals without signs or symptoms or respiratory disease. There are also limited data in interstitial lung disease, chest wall disease or bronchiectasis. P. Calverley illustrated with data from CRIM et al. [12] and their ECLIPSE study the degree of day-to-day variation in oscillatory mechanics compared to serial spirometry measurements taken over the same time period. This element of variability has implications for effective decision making when using the technique in the clinical setting, away from large population-based study groups. P. Calverley concluded that oscillometry is an important new tool that can help in disease management but cautioned it is not yet ready to use as a screening tool.

Multiple breath washout (MBW) technique is a helpful tool for assessing respiratory disease B. Thompson, Melbourne, Australia and P. Latzin, Bern, Switzerland

In the final "pro/con" debate B. Thompson pointed out that MBW is not a new technique; rather, it is well established in the research setting but has been slow to translate into the clinical setting. Through the work of RoBinson et al. [13], there is a published consensus statement for the MBW technique. He showed that STUART-ANDREws et al. [14] and VERBANCK et al. [15] have produced analysis techniques and equations to facilitate rapid quantification of MBW test findings. This work will support the application of the technique in the clinical setting and add to its ultimate clinical utility. According to B. Thompson, the clinical utility for the device can be demonstrated with published data from studies in asthma, COPD, lung transplantation, haematopoietic stem cell transplantation and idiopathic pulmonary fibrosis disease [16-20].

P. Latzin on the "con" side contended that the true clinical utility of MBW has not yet been defined and questioned the feasibility of its use in a clinical setting. P. Latzin argued that the interpretation of results is still not clear and more data are needed to show what the actual minimal clinically important difference is for MBW. The debate also raised the issue of lack of standardisation of software algorithms between manufacturers, along with the use of different gasses and system setups becoming obstacles to clear decision making in the clinical setting. During the oscillometry debate we heard how manufacturers can come together to work in harmony with clinicians and scientists to standardise and improve the clinical utility of emerging (and sometimes re-emerging) technologies. Perhaps this co-operation will be replicated for MBW.

\section{Current challenges and future directions}

B. Cooper, Edgbaston, UK

The debate was followed up with a talk on the current challenges and future direction of the Global Lung Function Initiative (GLI). B. Cooper spoke on behalf of the ERS GLI network. The initial stated purpose of the GLI was to derive internationally valid "all-age" spirometry reference equations with a specific focus on defining normal ranges and accurately representing ethnic differences. Reference ranges are important 
because they directly affect the interpretation of patient results $[21,22]$. The GLI reference values cover the life span and some ethnic populations (there was a call out for more data, see the GLI website: lungfunction.org) and provide insight into lung growth throughout puberty and in young adults. The GLI have since published reference values for spirometry and gas transfer testing (transfer factor for carbon monoxide (TLCO) $[23,24]$. The GLI values for TLCO allow for interpretation of TLCO in young children, during adolescence and during the transition from paediatric to adult care. The reference values for TLCO provide accurate estimates of limits of normal and avoid fixed cut-offs. The GLI have published toolkits to calculate reference values for spirometry and TLCO, thus making the GLI reference equations and related toolkits highly accessible and freely available for all to use (see: lungfunction.org). Before ending the session, B. Cooper offered insight into the future of the GLI, with objectives being to produce reference values for 1) respiratory muscle pressures; 2) cardiopulmonary exercise testing; 3) oscillometry; 4) airways resistance; and 5) exhaled nitric oxide levels.

\section{Symposium on the respiratory muscles at rest, during exercise and in the critically ill patient}

In this session, four expert speakers provided an update on the latest knowledge about respiratory muscle dysfunction, its evaluation and management.

\section{Respiratory muscle dysfunction in COPD: update on causes and biological findings \\ S. Vergès, Grenoble, France}

The muscle dysfunction observed in patients with COPD features reductions in muscle strength and muscle endurance [25]. Previous evidence indicates that the dysfunction does not occur equally in both peripheral and respiratory muscles [26]. There are larger reductions in muscle strength in the respiratory muscles than in peripheral muscles [26]. As a consequence, patients with important muscle dysfunction may present with reduced quality of life, increased mortality and impaired exercise tolerance [25]. Specific to the respiratory muscles, muscle dysfunction is linked to symptoms of dyspnoea and has a role in respiratory failure. There are some known factors affecting respiratory muscle function in patients with COPD. The chronic overload of respiratory muscles imposes some level of chronic fatigue to the muscles. Static and dynamic hyperinflation alter chest mechanics leading to a reduced ability of a shortened diaphragm to produce pressure and an increased elastic load that needs to be overcome by the respiratory muscles [27]. The acute effects of dynamic hyperinflation play an important role in disturbing load-capacity balance of the respiratory muscles and contribute to breathlessness during physical activity. Other factors contributing to muscle dysfunction include cigarette smoking, malnutrition, ageing, comorbidities, concomitant treatments, exacerbations, reduced physical activity levels and epigenetic factors. It is, therefore, important to measure respiratory muscle function. Muscle strength can be assessed by voluntary and evoked manoeuvres, while muscle endurance can be assessed using time limits during resistive breathing or isocapnic hyperpnoea [25]. More details on muscle testing will be discussed in the upcoming ERS statement on respiratory mechanics and muscle testing at rest and during exercise.

\section{Neural respiratory drive in respiratory disease patients \\ C. Jolley, London, UK}

Respiratory drive originates from the respiratory centres and is tightly linked to the load-capacity balance of the respiratory muscles [28]. A common consequence of an increased drive (caused by load-capacity imbalance) is the presence of breathlessness [28]. Although breathlessness is a disabling symptom in patients with severe disease, it is also highly prevalent in earlier stages of the disease, especially during physical exertion [29]. In patients with COPD, there is a typical increase in end-expiratory lung volume during exertion termed dynamic hyperinflation [30]. As consequence, there is an increase in the work of breathing accompanied by a reduction in capacity of the respiratory muscles during exercise resulting in increased diaphragm muscle activation [31]. Patients with COPD experience a neuromechanical uncoupling between an increased neural respiratory drive and a plateau in force generation of the diaphragm [32]. In other words, as the intensity of an exercise increases patients will try very hard to breath, but ineffective thoracic mechanics will hamper increases in ventilation leading to breathlessness [28]. C. Jolley also showed that neuromechanical uncoupling occurs in conditions other than COPD. Patients with cystic fibrosis [33] and interstitial lung diseases [34] experience a close relationship between increases of both muscle activation and symptoms of dyspnoea. SCHAEFFER et al. [35] recently published a study showing neural respiratory drive to be an independent predictor of breathlessness in fibrotic interstitial lung disease patients.

The respiratory muscles in intensive care unit patients

A. Demoule, Paris, France

A large proportion of patients with respiratory failure admitted to an intensive care unit experience acute diaphragm dysfunction $24 \mathrm{~h}$ after intubation [36]. During an intensive care stay, patients also experience 
ventilator-induced diaphragm dysfunction (i.e. reductions in muscle force, ultrastructural injuries and decreased cross-sectional area of diaphragm fibres) that worsens with longer periods of mechanical ventilation [37]. Mechanical ventilation also unloads respiratory muscles and evidence suggests there is a progressive reduction of diaphragm thickness that worsens over time [38]. Patients also experience intensive care unit-acquired neuromuscular muscle disorders due to infections, hyperglycaemia, neuromuscular blockers and other factors. As a consequence, there is a high prevalence of diaphragm dysfunction [39], even in patients who recover from illness and are eligible to wean from mechanical ventilation. The presence of the dysfunction is linked to weaning failure [40]. A cost-effective way to evaluate diaphragm dysfunction is the use of diagnostic ultrasound, with measurements of diaphragm excursion and thickness appearing most useful. Low values of either excursion or thickness are directly linked to diaphragm dysfunction $[40,41]$ and intubation risk in patients with COPD [42].

\section{Respiratory muscles/mechanics and dyspnoea in disease: what kind of rehabilitation?}

\section{R. Gosselink, Leuven, Belgium}

Rehabilitation aims to restore the balance between load and capacity of the respiratory pump [27]. This can be done by either unloading the pump (e.g. reducing work of breathing or ventilatory requirements, improving gas exchange, removing secretions) or by increasing the capacity of the pump (e.g. with inspiratory muscle training (IMT)). In stable patients, IMT used in isolation confers benefits across several outcomes [43], whilst its combination with exercise training might be useful to a specific group of patients with respiratory muscle weakness [43,44]. One recurrent problem of IMT is the way it is delivered. Current evidence of the benefits of IMT using mechanical threshold loading (Threshold IMT; Philips N.V., Amsterdam, the Netherlands) has the limitation that the method is mostly delivered as home-based unsupervised training with limited control on quality and quantity of the training stimulus. Tapered flow resistive loading (TFRL), by contrast, allows the therapist to store all the information about sessions in the device allowing a better monitoring of the training [45]. R. Gosselink also pointed to other important physiological differences between the two devices [45]. A recent study demonstrated that TFRL combined with pulmonary rehabilitation for patients with respiratory muscle weakness increased inspiratory muscle strength and endurance, increased duration and reduced symptoms at isotime during a constant workload endurance cycling test to a larger extent than a control group [46]. In critically ill patients, specifically those with difficult/prolonged weaning, IMT has been shown as an adjunct to the treatment of patients with weaning failure to improve weaning success and reduce mechanical ventilation duration [47]. Importantly, in patients with severely impaired respiratory function, such as those with prolonged weaning, optimal IMT including TFRL may result in better training outcomes. Recently, the protocol of a randomised controlled trial comparing TFRL versus sham in patients that are difficult to wean has been published with no final data available at the moment (expected study completion: September 2021) [48].

\section{Symposium on dyspnoea: a multidimensional and multidisciplinary approach}

The symposium "Dyspnoea: a multidimensional and multidisciplinary approach" was chaired by Pierantonio Laveneziana and Janelle Yorke. The symposium provided an overview of state-of-the-art advances in the multidimensional and multidisciplinary aspects of dyspnoea by focusing on four themes: the neurophysiology of dyspnoea; exercise and dyspnoea; the multidimensional assessment of dyspnoea; and the clinical impact and management of dyspnoea. The session targeted a wide-ranging audience, including respiratory clinicians, scientists and healthcare policy makers from trainee levels to experienced consultant pulmonologists. The large audience in attendance was rewarded with a session of high quality that included presentations from several renowned experts in the field as well as a patient testimony from an individual living with COPD.

\section{Multidimensional assessment methods for dyspnoea profiling in clinical practice and laboratory research \\ C. Morelot-Panzini, La Varenne Saint-Hilaire, France}

As there is widespread appreciation that dyspnoea is a multidimensional experience, attendees were offered a detailed overview of some of the leading instruments emerging as the most suitable candidates for its comprehensive measurement. The Multidimensional Dyspnoea Profile (MDP) [49] and Dyspnoea-12 are fast gaining recognition as important instruments for this purpose. While both share similar psychometric properties at the level of single and subdomain scores, the instruments were clarified as serving different purposes and pertaining to different sensations or emotions, making them non-interchangeable [50]. C. Morelot-Panzini offered a detailed account of the strengths of the MDP, in particular, including data demonstrating its validity against a range of patient-reported outcomes and clinical data [51], its application in the field of pulmonary rehabilitation [52], and its associated determinants (physical activity type, depression and $\mathrm{FEV}_{1} \%$ ) in community-based people living with COPD [51]. We were reminded that differences in the sensory processing, affective and emotional experiences of dyspnoea between patients 
means simple quantification of dyspnoea intensity alone may fail to reflect the true effectiveness of interventions that improve important dyspnoea sub-domains such as the sensation of "unpleasantness".

\section{Patient testimonial}

K. Mogensen, Reykjavik, Iceland

This presentation reminded attendees of the precise reason for their engagement with ERS and dedication to the field of respiratory medicine: to improve the patient experience of living with chronic lung disease. K. Mogensen travelled to Paris to offer personal reflections that were raw, but honest, describing considerable frustration at the loss of his previous ability to rise early in the day and maintain high levels of physical activity in the community. Despite living with long-term oxygen therapy $24 \mathrm{~h}$ per day, $\mathrm{K}$. Mogensen has clearly adopted a proactive, positive approach to life that sees him exercise 4 days per week, including regular sessions in the pool. He reflected on the learned value of accepting his condition for what it is, and not feeling shame at carrying portable oxygen. He urged others living with chronic lung disease to "talk - talk to family, talk to friends, talk to anyone". K. Mogensen's closing remarks reflected his clear "can do" approach to living with COPD: he did not want to tell others what to do, instead urging them to "do whatever works, but do something!".

\section{Affective and emotional dimensions of dyspnoea in chronic lung disease A. von Leupoldt, Leuven, Belgium}

A. von Leupoldt explored the physiological basis of changes in electroencephalography in response to challenges, highlighting how functional magnetic resonance imaging can identify brainwave activation in the cerebellum in "anticipation" of dyspnoea. This led to an interesting area of research exploring the effect of catastrophising in chronic lung disease, commonly quantified by the Breathlessness Catastrophizing Scale. A. von Leupoldt highlighted the fascinating interrelationship between brain activation and structure that occurs in anticipation of dyspnoea, demonstrating that patients with COPD show enhanced neural activation in the hippocampus and amygdala, both of which are key areas in the processing of fear, aversive learning and pain. The assumption underpinning this observation is that increased activation of the hippocampus and amygdala in anticipation of increased dyspnoea closely relates to clinical characteristics such as reduced exercise capacity and quality of life, and positively correlates with disease duration [53]. Interestingly, increased COPD disease duration was also shown to relate to reduced grey matter volume in the anterior cingulate cortex [54], a key structure responsible for antinociception and regulation of emotional states, that is tightly interconnected with the amygdala [53].

\section{Common mechanisms of exertional dyspnoea in chronic lung disorders}

\section{O'Donnell, Kingston, Canada}

D. O'Donnell discussed the complex pathways that govern dyspnoea, particularly during exercise, and their relationship with the sensation of dyspnoea. The central factor underpinning this experience is a disruption to the physiological regulation of dyspnoea: a process governed by a deformity of "demand" (neural pathways in the brain) versus "capacity" (the lung mechanics). This deformity was proposed as responsible for the completely different patient experience of dyspnoea reported by people with COPD compared to that of healthy controls (e.g. the sensation of "air hunger") [34]. D. O'Donnell demonstrated through a typically elegant series of laboratory studies that the core mechanism explaining this deformity is dysfunction to inspiratory neural drive. As exertional dyspnoea is a problem encountered by patients across the spectrum of COPD severity, D. O'Donnell also reiterated the salient avoidance behaviours such as reductions in daily physical activity levels that are commonly adopted in order to minimise the onset of distressing respiratory sensations. It was interesting to note that dyspnoea in mild COPD appears largely explained by increased "wasted" ventilation in the physiological dead space, thereby heightening the drive to breathe and worsening the inspiratory mechanical constraints [55]. Linking patients' disproportionate dyspnoea to specific pulmonary function abnormalities raises the notion of symptoms being related to obstructive physiology, thereby identifying a potentially valuable treatment target for symptom control [56].

\section{Nonpharmacological interventions for the management of breathlessness \\ M. Johnson, Hull, UK}

The final speaker in this symposium eloquently tied together the previous presentations through a review of a novel model of care that encompasses a holistic approach to the management of dyspnoea. This "Breathing - Thinking - Functioning" model may serve as a useful framework for the development of dyspnoea clinics befitting comprehensive multidisciplinary care [57]. This model was developed after an extensive qualitative review of 101 studies that highlighted many negative impacts of dyspnoea upon daily life reported by people living with chronic lung disease (e.g. "the breathlessness feeds the anxiety, and the anxiety feeds the fear"). This model is only in its relative infancy (e.g. data regarding any optimal duration are currently lacking) but offers many opportunities for advanced practitioner roles for nursing, medical 
and allied health professionals. A brief overview of the many differing nonpharmacological approaches to patient care for the management of dyspnoea [58] was also provided, with particular attention given to the simple and effective, but under-utilised, strategy of portable hand-held fans [59]. The nonpharmacological intervention with the best evidence base in respiratory practice is pulmonary rehabilitation, yet this modality is still only provided for less than $4 \%$ of patients with COPD in the UK [60]. By contrast, we were reminded that several pharmacological therapies with significantly smaller demonstrated impacts are widely available [60]. This highlights the crucial role for more effective implementation of evidence-based respiratory medicine. Several important clinical research priorities were proposed in order to help boost the credibility of nonpharmacological interventions in the clinical community. These included a call for clearer definitions of nonpharmacological interventions; more investigations of them as single components; and greater learning of how and when they should be most effectively implemented [59].

\section{Concluding remarks}

We hope this review of some of the most memorable 2018 ERS International Congress sessions provides readers with a valuable insight into some of the emerging and future areas affecting clinical allied health practice. The authors also hope to inspire readers' enthusiasm about the value of keeping abreast of an ever-changing clinical landscape within their field of interest. With this in mind, the authors welcome everyone to join them in Madrid in 2019 for the next rendition of the highly successful ERS International Congress. Adiós!

Conflict of interest: M. Rutter has nothing to disclose. C. Camillo has nothing to disclose. P. Coss has nothing to disclose. A. Sajnic has nothing to disclose. A. McGowan has nothing to disclose. D. Langer has nothing to disclose. J. De Brandt has nothing to disclose. C. Osadnik reports receiving a Lung Foundation Australia/Boehringer-Ingelheim COPD Research Fellowship (unrelated to the present work).

Support statement: J. De Brandt is funded by the Flemish government. The Research of FWO Aspirant J. De Brandt is sponsored by FWO-grant \#11B4718N. C. Osadnik was the recipient of a Lung Foundation Australia/BoehringerIngelheim COPD Research Fellowship, but has no conflicts to declare. Funding information for this article has been deposited with the Crossref Funder Registry.

\section{References}

1 Wanger J, Clausen JL, Coates A, et al. Standardisation of the measurement of lung volumes. Eur Respir J 2005; 26 511-522.

2 Dubois AB, Botelho SY, Comroe JH Jr. A new method for measuring airway resistance in man using a body plethysmograph: values in normal subjects and in patients with respiratory disease. J Clin Invest 1956; 35: 327-335.

3 Dubois AB, Botelho SY, Bedell GN, et al. A rapid plethysmographic method for measuring thoracic gas volume: a comparison with a nitrogen washout method for measuring functional residual capacity in normal subjects. J Clin Invest 1956; 35: 322-326.

4 GOLD. Global Strategy for the Diagnosis, Management and Prevention of COPD, Global Initiative for Chronic Obstructive Lung Disease (GOLD), 2018. Available from: https://goldcopd.org

5 Vestbo J, Edwards LD, Scanlon PD, et al. Changes in forced expiratory volume in 1 second over time in COPD. N Engl J Med 2011; 365: 1184-1192.

6 Nishimura K, Izumi T, Tsukino M, et al. Dyspnea is a better predictor of 5-year survival than airway obstruction in patients with COPD. Chest 2002; 121: 1434-1440.

7 Patterson MF, Borish L, Kennedy JL. The past, present, and future of monoclonal antibodies to IL-5 and eosinophilic asthma: a review. J Asthma Allergy 2015; 8: 125-134.

8 Pavord ID, Korn S, Howarth P, et al. Mepolizumab for severe eosinophilic asthma (DREAM): a multicentre, double-blind, placebo-controlled trial. Lancet 2012; 380: 651-659.

9 Burney PG, Hooper R. Forced vital capacity, airway obstruction and survival in a general population sample from the USA. Thorax 2011; 66: 49-54.

10 Kohlhäufl M, Brand P, Scheuch G, et al. Impulse oscillometry in healthy nonsmokers and asymptomatic smokers: effects of bronchial challenge with methacholine. J Aerosol Med 2001; 14: 1-12.

11 Oppenheimer BW, Goldring RM, Herberg ME, et al. Distal airway function in symptomatic subjects with normal spirometry following World Trade Center dust exposure. Chest 2007; 132: 1275-1282.

12 Crim C, Celli B, Edwards LD, et al. Respiratory system impedance with impulse oscillometry in healthy and COPD subjects: ECLIPSE baseline results. Respir Med 2011; 105: 1069-1078.

13 Robinson PD, Latzin P, Verbanck S, et al. Consensus statement for inert gas washout measurement using multiple- and single- breath tests. Eur Respir J 2013; 41: 507-522.

14 Stuart-Andrews CR, Kelly VJ, Sands SA, et al. Automated detection of the phase III slope during inert gas washout testing. J Appl Physiol (1985) 2012; 112: 1073-1081.

15 Verbanck S, Thompson BR, Schuermans D, et al. Ventilation heterogeneity in the acinar and conductive zones of the normal ageing lung. Thorax 2012; 67: 789-795.

16 Thomson NC, Chaudhuri R, Heaney LG, et al. Clinical outcomes and inflammatory biomarkers in current smokers and exsmokers with severe asthma. J Allergy Clin Immunol 2013; 131: 1008-1016.

17 Verbanck S, Schuermans D, Meysman M, et al. Noninvasive assessment of airway alterations in smokers: the small airways revisited. Am J Respir Crit Care Med 2004; 170: 414-419.

18 Thompson BR, Hodgson YM, Kotsimbos T, et al. Bronchiolitis obliterans syndrome leads to a functional deterioration of the acinus post lung transplant. Thorax 2014; 69: 487-488. 
19 Lahzami S, Schoeffel RE, Pechey V, et al. Small airways function declines after allogeneic haematopoietic stem cell transplantation. Eur Respir J 2011; 38: 1180-1188.

20 Nyilas S, Schreder T, Singer F, et al. Multiple breath washout: A new and promising lung function test for patients with idiopathic pulmonary fibrosis. Respirology 2018; 23: 764-770.

21 Brazzale DJ, Hall GL, Pretto JJ. Effects of adopting the new global lung function initiative 2012 reference equations on the interpretation of spirometry. Respiration 2013; 86: 183-189.

22 Quanjer PH, Brazzale DJ, Boros PW, et al. Implications of adopting the Global Lungs Initiative 2012 all-age reference equations for spirometry. Eur Respir J 2013; 42: 1046-1054.

23 Quanjer PH, Stanojevic S, Cole TJ, et al. Multi-ethnic reference values for spirometry for the 3-95-yr age range: the global lung function 2012 equations. Eur Respir J 2012; 40: 1324-1343.

24 Graham BL, Brusasco V, Burgos F, et al. 2017 ERS/ATS standards for single-breath carbon monoxide uptake in the lung. Eur Respir J 2017; 49: 1600016.

25 Maltais F, Decramer M, Casaburi R, et al. An official American Thoracic Society/European Respiratory Society statement: update on limb muscle dysfunction in chronic obstructive pulmonary disease. Am J Respir Crit Care Med 2014; 189: e15-e62.

26 Gosselink R, Troosters T, Decramer M. Distribution of muscle weakness in patients with stable chronic obstructive pulmonary disease. J Cardiopulm Rehabil 2000; 20: 353-360.

27 Moxham J. Failure of the respiratory muscle pump. Int Anesthesiol Clin 1984; 22: 165-181.

28 Jolley CJ, Moxham J. A physiological model of patient-reported breathlessness during daily activities in COPD Eur Respir Rev 2009; 18: 66-79.

29 Rennard S, Decramer M, Calverley PM, et al. Impact of COPD in North America and Europe in 2000: subjects perspective of Confronting COPD International Survey. Eur Respir J 2002; 20: 799-805.

30 Puente-Maestu L, Stringer WW. Hyperinflation and its management in COPD. Int J Chron Obstruct Pulmon Dis 2006; 1: 381-400.

31 Jolley CJ, Luo YM, Steier J, et al. Neural respiratory drive in healthy subjects and in COPD. Eur Respir J 2009; 33: 289-297.

32 Sinderby C, Spahija J, Beck J, et al. Diaphragm activation during exercise in chronic obstructive pulmonary disease. Am J Respir Crit Care Med 2001; 163: 1637-1641.

33 Reilly CC, Ward K, Jolley CJ, et al. Neural respiratory drive, pulmonary mechanics and breathlessness in patients with cystic fibrosis. Thorax 2011; 66: 240-246.

34 Faisal A, Alghamdi BJ, Ciavaglia CE, et al. Common mechanisms of dyspnea in chronic interstitial and obstructive lung disorders. Am J Respir Crit Care Med 2016; 193: 299-309.

35 Schaeffer MR, Ryerson CJ, Ramsook AH, et al. Neurophysiological mechanisms of exertional dyspnoea in fibrotic interstitial lung disease. Eur Respir J 2018; 51: 1701726.

36 Demoule A, Jung B, Prodanovic $\mathrm{H}$, et al. Diaphragm dysfunction on admission to the intensive care unit. Prevalence, risk factors, and prognostic impact-a prospective study. Am J Respir Crit Care Med 2013; 188: 213-219.

37 Jaber S, Petrof BJ, Jung B, et al. Rapidly progressive diaphragmatic weakness and injury during mechanical ventilation in humans. Am J Respir Crit Care Med 2011; 183: 364-371.

38 Goligher EC, Fan E, Herridge MS, et al. Evolution of diaphragm thickness during mechanical ventilation. impact of inspiratory effort. Am J Respir Crit Care Med 2015; 192: 1080-1088.

39 Demoule A, Molinari N, Jung B, et al. Patterns of diaphragm function in critically ill patients receiving prolonged mechanical ventilation: a prospective longitudinal study. Ann Intensive Care 2016; 6: 75.

40 Dres M, Mancebo J, Curley GF. Update in critical care 2015. Am J Respir Crit Care Med 2016; 194: 19-25.

41 Li C, Li X, Han H, et al. Diaphragmatic ultrasonography for predicting ventilator weaning: A meta-analysis. Medicine (Baltimore) 2018; 97: e10968.

42 Marchioni A, Castaniere I, Tonelli R, et al. Ultrasound-assessed diaphragmatic impairment is a predictor of outcomes in patients with acute exacerbation of chronic obstructive pulmonary disease undergoing noninvasive ventilation. Crit Care 2018; 22: 109.

43 Spruit MA, Singh SJ, Garvey C, et al. An official American Thoracic Society/European Respiratory Society statement: key concepts and advances in pulmonary rehabilitation. Am J Respir Crit Care Med 2013; 188: e13-e64.

44 Camillo CA, Osadnik CR, van Remoortel H, et al. Effect of 'add-on' interventions on exercise training in individuals with COPD: a systematic review. ERJ Open Res 2016; 2: 00078-2015.

45 Langer D, Charususin N, Jacome C, et al. Efficacy of a novel method for inspiratory muscle training in people with chronic obstructive pulmonary disease. Phys Ther 2015; 95: 1264-1273.

46 Charususin N, Gosselink R, Decramer M, et al. Randomised controlled trial of adjunctive inspiratory muscle training for patients with COPD. Thorax 2018; 73: 942-950.

47 Elkins M, Dentice R. Inspiratory muscle training facilitates weaning from mechanical ventilation among patients in the intensive care unit: a systematic review. J Physiother 2015; 61: 125-134.

48 Hoffman M, Van Hollebeke M, Clerckx B, et al. Can inspiratory muscle training improve weaning outcomes in difficult to wean patients? A protocol for a randomised controlled trial (IMweanT study). BMJ Open 2018; 8: e021091.

49 Banzett RB, O’Donnell CR, Guilfoyle TE, et al. Multidimensional Dyspnea Profile: an instrument for clinical and laboratory research. Eur Respir J 2015; 45: 1681-1691.

50 Williams MT, John D, Frith P. Comparison of the Dyspnoea-12 and Multidimensional Dyspnoea Profile in people with COPD. Eur Respir J 2017; 49: 1600773.

51 Morelot-Panzini C, Gilet H, Aguilaniu B, et al. Real-life assessment of the multidimensional nature of dyspnoea in COPD outpatients. Eur Respir J 2016; 47: 1668-1679.

52 Herigstad M, Hayen A, Reinecke A, et al. Development of a dyspnoea word cue set for studies of emotional processing in COPD. Respir Physiol Neurobiol 2016; 223: 37-42.

53 Esser RW, Stoeckel MC, Kirsten A, et al. Brain activation during perception and anticipation of dyspnea in chronic obstructive pulmonary disease. Front Physiol 2017; 8: 617. 
54 Esser RW, Stoeckel MC, Kirsten A, et al. Structural brain changes in patients with COPD. Chest 2016; 149: 426-434.

55 Neder JA, Berton DC, Muller PT, et al. Ventilatory inefficiency and exertional dyspnea in early chronic obstructive pulmonary disease. Ann Am Thorac Soc 2017; 14: Suppl. 1, S22-SS9.

56 Mahler DA, O’Donnell DE. Recent advances in dyspnea. Chest 2015; 147: 232-241.

57 Spathis A, Booth S, Moffat C, et al. The Breathing, Thinking, Functioning clinical model: a proposal to facilitate evidence-based breathlessness management in chronic respiratory disease. NPJ Prim Care Respir Med 2017; $27: 27$.

58 Bausewein C, Booth S, Gysels M, et al. Non-pharmacological interventions for breathlessness in advanced stages of malignant and non-malignant diseases. Cochrane Database Syst Rev 2008; 2: CD005623.

59 Booth S, Moffat C, Burkin J, et al. Nonpharmacological interventions for breathlessness. Curr Opin Support Palliat Care 2011; 5: 77-86.

60 National Collaborating Centre for Chronic Conditions. Chronic obstructive pulmonary disease. National clinical guideline on management of chronic obstructive pulmonary disease in adults in primary and secondary care. Thorax 2004; 59: Suppl. 1, 1-232. 